be subsidized, largely by the member firms of the Slough Industrial Health Service. Now with a new Council of Management, Dr. Hickish the occupational hygiene engineer as Director, and other staff modifications, the service has been launched on its own. The Nuffield Foundation has given a grant of up to $£ 20,000$ over five years by which time the Service is expected to be a selfsupporting commercial proposition.

While the need for occupational hygiene services remains great especially in smaller factories, the demand increases slowly. Services such as the one at Slough, the North of England Industrial Hygiene advisory service based on Durham University and the one at Manchester University, will help to increase the demand and ascertain the best ways of meeting it. The new training courses for occupational health engineers at the London School of Hygiene and Tropical Medicine will help to train staff for these services. However, no other form of health service concerned with prevention has developed on a fee for service basis, and occupational hygiene is not likely to be an exception. This means that while large industrial organizations and a few others supported by the Nuffield Foundation may run successful occupational hygiene services the vast majority of industry will go without until some Government department-presumably the Ministry of Labour-undertakes its long overdue task.

\section{H. Woop}

Control of Airborne Dust. By W. D. Bamford. (Pp. viii +479 ; illustrated. $65 s$., to members of the Association; 84s. to non-members.) Birmingham: The British Cast Iron Research Association. 1961

This volume is a blend of reports of original work relating to the formation, movement, and control of dust clouds, and textbook material dealing with heating, fan engineering, and air cleaning. There is therefore a wealth of useful information for the engineer concerned with dust control.

The primary interest of the author has been the control of dust in foundries, and special attention is paid to thermal currents, knock-outs, and abrasive wheels. Nevertheless the principles enunciated should be capable of application to other dust and fume problems.

Experimental methods and results are given in detail, and while this does not make for ease of reading for the general reader it will probably be welcomed by those who use the book with a specific problem in mind.

\section{E. HICKISH}

Aktuelle Probleme der Staublungenforschung. Tagungsbericht zum 10, Kongress der Süddeutschen TuberkuloseGesellschaft in Beyreuth vom 1, bis 3, Juni 1961. Edited by H. Hofmann. (Pp. 163; 74 figures + tables. DM. 13.80.) Stuttgart: Georg Thieme. 1962.

Some 14 papers by eminent German authorities on dust disease are presented in this volume along with some short reports of the discussion. Very many of the medical aspects of the pneumoconiosis problem are touched on, and some papers range over a great part of the subject. Some points of special interest are: special types of pneumoconiosis; bronchitis and emphysema in persons exposed to dust, silico-tuberculosis; and prophylaxis and treatment of dust disease of the lungs. One special type of pneumoconiosis becoming more common presents radiologically a very fine diffuse generalized nodulation, a lattice-net appearance, which may be better seen by the use of a special $x$-ray technique. This "pin-head" type is due to mixed dust containing much coal dust with little silica, and by damaging the pulmonary circulation leads to right heart failure. A second type of pneumoconiosis, Caplan's syndrome, is discussed by Dr. Worth and Dr. Fritze. Dr. Sepke states that reticulum cells appear in the blood in 80 to $90 \%$ of such cases to the extent of about 2 to $11 \%$, but are rarely found in the blood of ordinary silicotic patients. The third type of interest is that presenting egg-shell calcification of the hilus, without nodulation. Dr. Ahlendorf puts in a plea that this type should be recognized for compensation purposes as silicosis causing disability. His cases largely occur in slate workers.

Bronchitis and emphysema and their sequelae in workers exposed to dust are naturally mentioned by many of the contributors and are the subject of two papers. Dr. Carstens in a discussion gives his view that dust lung disease is not merely silicosis but is a complex of specific and unspecific reactions of the lung to dust, which are independent in their causes. This complex includes silicosis, asthmatic emphysema, bronchitis, bronchiectasis, and probably atrophy resulting from the dust. The whole question of the relation of dust inhalation to bronchitis and emphysema is reviewed in a paper by Dr. H. Valentin. The conclusion he draws is that a causal connexion between the two has not been proved.

Silico-tuberculosis is compensatable Disease No. 35 in the new 6th Regulation. It is entitled "Silicosis combined with active tuberculosis", a definition which differs from that of the previous 5th Regulation which used the expression "active-progressive tuberculosis". This point as well as many other features of the combined disease is thoroughly discussed by various contributors. However silico-tuberculosis in modern times is much less frequent in trades such as the pottery, moreover the addition of tuberculosis does not lessen the expectation of life of silicotics as it did. The treatment of tuberculosis in the presence of silicosis is difficult and Dr. H. Roth says that conservative treatment to be successful must be started as soon as tuberculosis is suspected, and should be intensive and persisted in from eight to $\mathbf{4 8}$ months. But $60 \%$ of patients receive none or only temporary benefit from chemotherapy, so operative measures are employed and nowadays that means resection. On the results of this treatment in pottery workers, which are not very encouraging, Roth makes an appeal for the institution of prophylactic measures.

Treatment and medical prophylaxis are dealt with by Dr. J. Klippel in a very comprehensive way. Methods developed from modern investigations into silicosis such as cortisone treatment, aluminium inhalation, aerosol treatment, have not proved very successful. The symptomatic treatment of the various complications, bronchitis and emphysema, bronchiectasis and so on up to right heart failure are considered very fully, especially from the 
point of view of the effect of different remedies. Treatment in institutions in places with suitable climates is carried out by the pottery companies, and effects improvement in the dyspnoea, cough, and sputum.

An interesting monograph by H.-W. Schlipköter describes the results of animal experiments with a substance which limits the fibrosis produced by quartz. Schlipköter does not however claim that this is a new silicosis therapy.

From a study of this report it is evident that the members of the South German Tuberculosis Society had an interesting and informative meeting. This volume brings them up to date with present-day thought in Germany on pneumoconiosis.

\section{Chari_es L. Sutherland}

Lunge und Berufskrankheiten. Klinische und Pathologisch-anatomische Gutachten. Edited by Herbert Trautmann. (Pp. xi + 259; 26 figures. DM.38.) Stuttgart: George Thieme. 1962.

This is volume 73 of the Work and Health series of publications issued from the Department of the Federal Ministry for Work and Social Order. The recent publication of the 6th Regulation extending accident insurance to 47 occupational diseases or groups of diseases seems to have stimulated interest in the compensation aspect of these diseases. This book is a collection of opinions of prominent authorities in 63 illustrative cases presenting different types of compensation problems in occupational diseases of the lungs. These problems may have arisen either from difficulty in interpreting the regulations or more often in assessing the relative influence of the insurable disease and of some intercurrent disease in producing compensatable impairment. In the United Kingdom, while they are of interest to chest physicians and pathologists, these matters are decided by medical Boards, tribunals, and Commissioners appointed by the Ministry of Pensions and National Insurance. Certain important decisions in cases referred to Commissioners are published but so far no compilation of decisions such as this has been made.

Of the 63 cases no fewer than 31 are connected with problems arising from silicosis; 10 more would probably also be dealt with in this country by Pneumoconiosis Boards. In Germany compensation is paid, not because silicosis is present but only when it causes impairment of the function of the respiratory or circulatory organs. An early silicosis of itself is not considered an occupational disease. The percentage disablement is not based on lung function measurements alone but on a combination of slinical, radiological, and spirometrical evidence. Examples are given of how all this works out in practice especially in the presence of such conditions as egg-shell calcification and focal emphysema. Four cases illustrate the combination of silicosis and tuberculosis, i.e. silicotuberculosis, which is one of the compensatable diseases, No. 35 of the 6th Regulation. Before a diagnosis of this combined disease is made, a silicotic nodulation and an active tuberculosis must both be present. A most interesting part of the book treats of cases involving the associa- tion of silicosis with intercurrent disease. Such conditions are bronchitis and emphysema, pneumonia, cancer, coronary disease, and Caplan's syndrome. Silicosis is not considered to be a cause of lung cancer, but one case is quoted where a causal connexion between an extensive silicosis and a carcinoma was recognized. The lung cancer, although there were metastases in liver and bones, was limited to a small area of the right upper lobe. It had arisen in the wall of a small bronchus which was also infiltrated with silicotic tissue.

The influence of silicosis in contributing to a death due to an independent condition is admitted if the death has been accelerated by about a year. In deaths from coronary thrombosis, the death is not associated with the silicosis unless it is severe enough to produce evidence of right heart strain. No case of cerebral haemorrhage is discussed, although there is mention of a case of cerebral tumour.

Apart from several other lung conditions due to dust such as asbestosis, aluminosis, and siderosis, a variety of lung conditions associated with industrial poisons are exemplified by cases. The production of asthma from exposure to arsenic, flour, or streptomycin is discussed since this condition comes under Disease No. 41, Bronchial Asthma, if it leads to giving up the occupational activity or any remunerative work. On the other hand asthma caused by the inhalation of E.605 is part of a general poisoning-No. 14, Illness due to Phosphorus or its compounds.

A chapter devoted to occupational tuberculosis discusses the relative risk in general and tuberculosis hospitals and the different risks of laboratory, $x$-ray work, and bedside nursing. The risk from familial infection may be most important. Sarcoidosis-developing in a ward maid, permits a detailed consideration of the relation of sarcoid and tuberculosis. The decision was that sarcoidosis unless it was originally combined with tuberculosis or had passed over into tuberculosis, was not an occupational disease. Bovine tuberculosis occurring in slaughterhouse workers is a compensatable disease under Disease No. 38, Diseases transferred from animals to man; in the particular case it was conceded that bovine tuberculosis had worsened an old childhood tuberculosis.

This chapter on tuberculosis shows that the subject matter may range beyond the limits of questions of compensation. On the whole, however, the appeal of this book will be most to those dealing with compensation problems. It is more than possible that some of the decisions would not be acceptable in this country.

\section{Charles L. Sutherland}

Cardiacs and Diabetics in Industry: A Study in Work Experience. By Grace Wyshak, L. S. Snegireff, and Augusta Law. (Pp. xviii $+260 ; 37$ tables and 12 graphs. 86s.) Springfield, Illinois: Thomas; Oxford: Blackwell Scientific Publications. 1961.

This fascinating study in work experience comes from the Harvard School of Public Health. It is not a study of the prevalence of cardiovascular and diabetic disease in industry, but a study of some 700 employees diagnosed 